\title{
Functional characteristic of PC12 cells with reduced microsomal glutathione transferase $1^{*}$
}

\author{
Monika Sobczak ${ }^{\star}$, Tomasz Boczek ${ }^{1 \star}$, Bozena Ferenc ${ }^{1}$, Joanna Taha ${ }^{1}$, Anna Kozaczuk', \\ Magdalena Wiktorska², Izabela Sacewicz-Hofman², Jolanta Niewiarowska² \\ and Ludmila Zylinska ${ }^{1}$
}

'Department of Molecular Neurochemistry; and 2Department of Molecular and Medical Biophysics, Medical University, Łódź, Poland

\begin{abstract}
Microsomal glutathione transferase 1 (MGST1) possesses glutathione transferase and peroxidase activities and is active in biotransformation of xenobiotics and in defense against oxidative stress. To assess MGST1 role in the development and functioning of PC12 cells, we constructed a cell line with reduced MGST1 (PC12_M). Real-time PCR and immunoblot assays showed MGST1 expression lowered to $60 \%$ and immunocytochemical analyses demonstrated an altered concentration and distribution of the enzyme. PC12_M cells revealed a larger tendency to grow in clusters, weaker adhesion, irregular shape of bodies, short neurite outgrowth and higher percentage of necrotic cells (34\%). The total GSTs activity determined with non-specific substrate CDNB (1-chloro-2,4-dinitrobenzene) decreased by 15-20\%, whereas that with DCNB (2,4-dichloro-1-nitrobenzene), a substrate more specific for cytosolic GSTs, was similar to the one in control cells. This suggests that reduction of MGST1 cannot be compensated by other glutathione transferases. In PC12_M cells the total glutathione content was higher by $15-20 \%$, whereas the GSSG/GSH ratio was lower than in control cells. Moreover, the laminin-dependent migration rate was much faster in control cells than in PC12_M, suggesting some alterations in the metastatic potential of the line with suppressed MGST1. The amount of MAP kinases (p38, JNK, ERK1/2) was elevated in PC12_M cells but their phosphorylation level declined. Microarray analysis showed changed expression of several genes, which may be linked with differentiation and necrosis of PC12_M cells. Our data suggest that MGST1 could be an important regulator of PC12 cells development and might have significant effects on cell growth and proliferation, probably through altered expression of genes with different biological function.
\end{abstract}

Keywords: microsomal glutathione transferase 1, PC12 cells; pseudoneuronal phenotype; necrosis; metastatic potential; signaling pathways

Received: 25 August, 2010; revised: 22 November, 2010; accepted: 15 December, 2010; available on line: 17 December, 2010

\section{INTRODUCTION}

MGST1 (microsomal glutathione transferase 1) is a member of the MAPEG superfamily (membrane-associated proteins in eicosanoid and glutathione metabolism), which also includes LTC4 (leukotriene $\mathrm{C}_{4}$ ) synthase, FLAP (5-lipoxygenase-activating protein), MGST2 and MGST3 (microsomal glutathione transferase 2 and 3) and MGST1-L1 (microsomal glutathione transferase 1-like 1) (Jakobbson et al., 2000). Northern blot analysis showed that in rats the highest level of mRNA MGST1 was detected in the liver. Taking the amount in the liver as $100 \%$, the MGST1 expression levels in some other tissues were: adrenal gland $13 \%$, uterus $11 \%$, stomach $8 \%$, kidneys $6 \%$, testis $5 \%$ and small intestine $3.8 \%$ (Estonius et al., 1999). High amounts of MGST1 are detected in the endoplasmic reticulum, in the outer mitochondrial and plasma membranes of hepatocytes what is related to a specific role of this cell type. However, even lower presence of the enzyme in extra-hepatic tissues appears to be physiologically significant (Siritantikorn et al., 2007).

MGST1 is a homotrimeric protein with a molecular mass of $51.9 \mathrm{kDa}$. Each subunit contains a single cysteine (Cys49), which is modified by many substrates, which increases the activity of the enzyme. MGST1 has been shown to be activated by reactive oxygen $\left(\mathrm{O}_{2}{ }^{-}\right.$, $\mathrm{H}_{2} \mathrm{O}_{2}$ ) and nitrogen (ONOO ${ }^{-}$, NO) species, sulfhydryl reagents, proteolysis, heating, radiation and dimerization of the homotrimers (Imaizumi et al., 2006; Yanbin et al., 2006). The enzyme has glutathione transferase and

e-mail: ludmila.zylinska@umed.lodz.pl

* Both authors contributed equally to this work

* Some of the data were presented at the $35^{\text {th }}$ FEBS (Federation of European Biochemical Societies) Congress in Göeteborg, Sweden, June 26-July 2, 2010.

Abbreviations: Ache, acetylcholinesterase; Bad, BCL2-associated agonist of cell death; Bax, BCL2-associated X protein; BCL2, apoptosis regulator $\mathrm{BCl}-2$; $\mathrm{BCl}-\mathrm{W}$, apoptosis regulator $\mathrm{BCL}-\mathrm{W}$; $\mathrm{BCl}-\mathrm{x}$, BCL2-like 1; Bmp2, bone morphogenetic protein 2; Cdk5, cyclin dependent kinase 5; Chrm1, cholinergic receptor, muscarinic 1; CDNB, 1-chloro-2,4-dinitrobenzene; DAPI, 4,6-diamidine-2-phenylindole; DCNB, 2,4-dichloro-1-nitrobenzene; DTNB, 5,5-dithiobis(2-nitrobenzoic acid); Efna 1, ephrin 1; ERK1 and ERK2, extracellular signalregulated kinase 1 and 2; Fmr1, fragile mental retardation 1; Gpi, glucose-6-phosphate isomerase; GSH, reduced glutathione; GSSG, glutathione disulfide; GSTs, glutathione transferases; GSX, total glutathione; 4-HNE, 4-hydroxy-2-nonenal; JNK, c-Jun N-terminal kinase; Kcnip2, Kv channel interacting protein 2; L1 cam, L1 cell adhesion molecule; Limk1, LIM domain kinase 1; MGST1, microsomal glutathione transferase 1; Mtch1, mitochondrial carrier homolog 1 (C. elegans); Myh10, cellular myosin heavy chain, type B; NcoA6, nuclear receptor coactivator 6; Ngfr, nerve growth factor receptor; Ninj, ninjurin; Nrg1, neuregulin 1; Nrtn, neurturin; Pafah1b1, platelet-activating factor acetylhydrolase; Pax2, paired box 2; p38 MAPK, p38 mitogen activated protein kinase; Rac1, ras-related C3 botulinum toxin substrate 1; Rasgrf1, Ras protein-specific guanine nucleotide-releasing factor 1; Rtn4, reticulon 4; S100a6, calcyclin; Stmn1, stathmin 1; Tiam1, T-cell lymphoma invasion and metastasis $1 ;$ TNB 5-thio-2-nitrobenzoic acid; Ywhah, tyrosine 3-monooxygenase/ tryptophan 5-monooxygenase activation protein, eta polypeptide 
peroxidase activities and due to these unique properties plays a major role in biotransformation of xenobiotics, participates in the promotion of anticancer drug resistance, protects membranes from lipid peroxidation and their toxic products, mainly 4-HNE (Lee \& DeJong, 1999; Yang et al., 2003; Johansson et al., 2007; Siritantikorn et al., 2007). MGST1 action is particularly important in the central nervous system since the age-related increase in reactive oxygen species is linked with the development of neurodegenerative disorders, such as Parkinson's and Alzheimer's diseases, multiple sclerosis and amyotrophic lateral sclerosis (Uttara et al., 2009; von Bernhardi et al., 2010).

The aim of our work was to elucidate the role of MGST1 on the viability, morphology and antioxidant system of PC12 cells derived from a transplantable rat pheochromocytoma, a line that is also frequently used as a model for the study of neuronal functions.

\section{MATERIALS AND METHODS}

Chemicals. All reagents were of analytical grade. The PC12 rat pheochromocytoma cell line, heat-inactivated fetal bovine serum and heat-inactivated horse serum were obtained from ATCC (USA). RPMI 1640 medium (with $25 \mathrm{mM}$ Hepes buffer, without L-glutamine) was from PAA (USA). Streptomycin and penicillin were from Polfa Tarchomin S.A. (Poland). Collagen type I from rat tail, L-glutamine, sodium pyruvate, $\mathrm{D}-(+)$ glucose solution $45 \%$, BSA, $0.1 \%$ Tween 20, Sigma Fast BCIP/ NBT, Glutathione Assay Kit, CDNB, DCNB, laminin, cocktail of proteases inhibitors, 4,6-diamidine-2-phenylindole (DAPI) and anti-goat IgG-FITC antibody were purchased from Sigma Aldrich (Germany). Total RNA Isolation Kit was from Epicentre Biotech. (USA). pCR ${ }^{\circledR} \mathrm{T} 7 /$ NT-TOPO vector and pcDNA3.1 $(+)$ were from Invitrogen (USA). MGST1 and GAPDH primers and oligo(dT) $)_{12-18}$ were from Institute of Biochemistry and Biophysics PAS (Warszawa, Poland). M-MLV reverse transcriptase was from Invitrogen Life Technologies (USA). dNTP was from Solis BioDyne (Estonia). SYBR Green Master Mix was purchased from Fermentas International Inc. (Canada). Nitrocellulose membrane 0.45 $\mu \mathrm{m}$ and Protein Assay Kit were from Bio-Rad Laboratories (USA). Primary antibodies against MGST1, $\beta$-actin, JNK, p-JNK, p38, pp-38, ERK1/2 and p-ERK1/2 were from Santa Cruz Biotechnology Inc. (USA). Annexin-VFLUOS Staining Kit was from Roche Diagnostic GmbH (Mannheim, Germany). ArrayGrade ${ }^{\mathrm{TM}}$ Total RNA Isolation Kit, Neurogenesis and Neural Stem Cell Oligo GEArray (ORN-404), TrueLabeling-AMP $2.0 \mathrm{Kit}$ and Chemiluminescent Detection Kit were from SABiosciences Corp. (Frederick, MD, USA). dUTP biotin was from Perkin Elmer (USA). G418 was from AppliChem $\mathrm{GmbH}$ (Germany). Trypan Blue was from Biowest LLC (USA). Vectashield® Mounting Medium was purchased from Vector Labs (USA). Eosin solution was purchased from PPH POCh S.A. (Poland). Hematoxylin solution was from AQUA-MEDICA (Poland).

Cell culture. PC12 cells were cultured on collagen (type I from rat tail) coated flasks in 85\% RPMI 1640 supplemented with $25 \mathrm{mM}$ Hepes buffer, $10 \%$ heat-inactivated horse serum and $5 \%$ heat-inactivated fetal bovine serum, $2 \mathrm{mM}$ L-glutamine, $1 \mathrm{mM}$ sodium pyruvate, $1 \mathrm{~g} / 1 \mathrm{D}-(+)$-glucose and antibiotics: $25 \mu \mathrm{g} / \mathrm{ml}$ streptomycin and $25 \mathrm{U} / \mathrm{ml}$ penicillin. Cells were maintained in a humidified incubator at $37^{\circ} \mathrm{C}$ in $5 \% \mathrm{CO}_{2}$ atmosphere.
The medium was exchanged every $48 \mathrm{~h}$. Cells were rinsed with $1 \times \mathrm{PBS} \mathrm{pH} 7.0$ and detached with $0.25 \%$ trypsin/EDTA. After centrifugation at $1000 \times g$ for 5 min cells were subcultured in $25 \mathrm{~cm}^{2}$ flasks using subcultivation ratio of $1: 2$ to $1: 4$ and were photographed every $24 \mathrm{~h}$ with an inverted microscope (Olympus CK40). Cells were passaged twice a week.

Plasmid construction and stable transfection. Vector carrying an antisense RNA sequence directed to MGST1 was constructed using standard recombinant DNA technologies. Briefly, cellular RNA was extracted from PC12 cells using Total RNA Isolation Kit according to the procedure provided by the manufacturer. One microgram of total RNA was then subjected to reverse transcription using oligo $(\mathrm{dT})_{12-18}$ primers. Amplified cDNA was used as a template to generate a 390-bp PCR product for MGST1 using the following primers: 5'-CGGATCCGCTCCTGAGCAGCCTGTAAGCAT-3' and 5'-CGAATTCATTGAAAGCATGGCTGACCT-3'. PCR conditions were as follows: $95^{\circ} \mathrm{C}$ for $2 \mathrm{~min}$, then $30 \mathrm{cy}-$ cles of: $95^{\circ} \mathrm{C}$ for $30 \mathrm{~s} ; 52^{\circ} \mathrm{C}$ for $60 \mathrm{~s} ; 72^{\circ} \mathrm{C}$ for $90 \mathrm{~s}$ and the final extension at $72^{\circ} \mathrm{C}$ for $5 \mathrm{~min}$. The PCR product was directly ligated to $\mathrm{pCR}^{\circledR} \mathrm{T} 7 / \mathrm{NT}$-TOPO vector. The BamHI/EcoRI restriction fragment containing 390 bp of MGST1 cDNA was subcloned in the antisense orientation in vector pcDNA3.1(+). The integrity and orientation of the insert was confirmed by restriction enzyme analysis and sequencing. Plasmid DNA was introduced into PC12 cells by electroporation and selection was initiated after 48 h. Stably transfected PC12_M cells were selected for antibiotic resistance with neomycin analog G418 at $800 \mu \mathrm{g} / \mathrm{ml}$. PC12 cells transfected with empty plasmid, expressing neomycin resistance alone, was used as a control (PC12). Both lines were maintained in complete RPMI 1640 medium containing $200 \mu \mathrm{g} / \mathrm{ml}$ G418.

Quantitative real-time PCR. Total cellular RNA and cDNA were prepared as described previously (Zylinska et al., 2007). Real-time PCR was carried out on an Abi PrismTM 7000 sequence detection system (Applied Biosystems) using a SYBR Green master mix and cDNA obtained from each cell line. The following primers were used: MGST1 5'-ATTGAAAGCATGGCTGACCT-3', 5'-GCTCCTGAGCAGCCTGTAAGCCAT-3' and GAPDH 5'-GGTTACCAGGGCTGCCT'TCT-3', 5'-CT'TCCCATTCTCAGCCT'TGACT-3'. Amplification was performed by $10 \mathrm{~min}$ at $95^{\circ} \mathrm{C}$ followed by 40 cycles at $95^{\circ} \mathrm{C}$ for $15 \mathrm{~s}$ and at $60^{\circ} \mathrm{C}$ for $60 \mathrm{~s}$. For each set, a melting curve was performed. Results are given as a relative expression rate of $m g s t 1$ normalized to gapdh houskeeping gene, determined using the comparative Ct $\left(2^{-\Delta \Delta \mathrm{Ct}}\right)$ method (Livak \& Schmittgen, 2001).

Trypan Blue staining. Cell viability was determined using the Trypan Blue staining. Cells were harvested, suspended in PBS and mixed with equal volume of $0.5 \%$ Trypan Blue solution. After $5 \mathrm{~min}$ at room temperature, viable and dead (stained) cells were counted using a hemocytometer under an inverted microscope using a $10 \times$ magnification.

Flow cytometry analysis. Flow cytometry analysis was performed using a Becton Dickinson FACSCalibur and Annexin-V-FLUOS Staining Kit. Cells were harvested, washed with PBS and centrifuged at $1000 \times g$ for $5 \mathrm{~min}$. Next, cells $\left(10^{4}\right)$ were resuspended in $100 \mu \mathrm{l}$ of Annexin-V-FLUOS labelling solution (100 $\mu \mathrm{l}$ Hepes buffer, $2 \mu \mathrm{l}$ Annexin-V-Fluorescein and $2 \mu \mathrm{l}$ propidium iodide) and incubated for $10-15 \mathrm{~min}$ at $15^{\circ} \mathrm{C}-25^{\circ} \mathrm{C}$ in the dark. The data were analyzed with Becton Dickinson CELLQuest software. 
Immunocytochemistry. PC12 cells were grown on LabTek II CC2 chamber slides (Nunc, USA) coated with collagen (type I from rat tail). On the next day the medium was removed, cells were washed with PBS, fixed with $3.8 \%$ paraformaldehyde in PBS for $15 \mathrm{~min}$, permeabilized with $0.1 \%$ Triton X-100 in PBS for $30 \mathrm{~min}$ and blocked with $6 \% \mathrm{BSA}$ in PBS for $3 \mathrm{~h}$ at room temp. Then, the coverslips were incubated overnight at $4{ }^{\circ} \mathrm{C}$ with primary anti-MGST1 antibodies $(1: 50)$ in $6 \%$ BSA in PBS. After several washes with PBS, cells were probed with FITC-conjugated anti-goat IgG secondary antibodies $(1: 400)$ for $2 \mathrm{~h}$ at room temp. Before mounting with Vectashield $^{\circledR}$ Mounting Medium, cell nuclei were stained with DAPI. Microscopy was carried out with a confocal laser-scanning microscope TCS SP5 (Leica).

Migration assay. The migration assay was performed using Transwell Costar ${ }^{\circledR}$ chambers containing polycarbonate membranes (diameter $-6.5 \mathrm{~mm}$ ) with $8 \mu \mathrm{m}$ pores, which were placed in 24-well plates. The wells were coated with $10 \mu \mathrm{g} / \mathrm{ml}$ laminin in PBS, pH 7.4 for $2 \mathrm{~h}$ at $37^{\circ} \mathrm{C}$ and filled with serum-free RPMI 1640 containing $0.5 \%$ BSA. PC12 and PC12_M cells $\left(1 \times 10^{6}\right)$ in $100 \mu \mathrm{l}$ serum-free RPMI 1640 containing $0.1 \%$ BSA were added to the chambers and allowed to migrate through the membranes under optimal conditions $\left(37^{\circ} \mathrm{C}\right.$, $5 \%\left(\mathrm{CO}_{2}\right)$ for $4 \mathrm{~h}$. After this time, cells found on the bottom side of the membranes were washed with PBS and fixed in $95 \%$ methanol. Next, the membranes were rinsed with PBS and stained with hematoxylin for $6 \mathrm{~min}$ and $0.25 \%$ eosin for $3 \mathrm{~min}$ at room temp. After staining they were washed with PBS and stained cells were counted under an inverted Nikon TMS-F microscope (magn. 20×). Non-specific migration was determined using $0.5 \%$ BSA as a control substrate.

Determination of glutathione content. Total glutathione (GSX) and glutathione disulfide (GSSG) was determined with Glutathione Assay Kit according to the manufacturer's protocol. Cells $\left(3 \times 10^{5}\right)$ were detached by trypsinization, centrifuged at $1000 \times g$ for $5 \mathrm{~min}$ and lysed with $10 \mathrm{mM} \mathrm{HCl}$. Next, the pellets were frozen at $-80^{\circ} \mathrm{C}$ and thawed at $37^{\circ} \mathrm{C}$. The samples were deproteinized with $5 \% 5$-sulfosalicylic acid and centrifuged at $8000 \times \mathrm{g}$ for $10 \mathrm{~min}$. Concentration of glutathione was determined in the supernatant. To block free thiols $(-\mathrm{SH})$, $80 \mathrm{mM} 4$-vinylpyridine solution was added and incubated for $30 \mathrm{~min}$ at room temp. The amount of glutathione in the biological samples was determined from a standard curve of reduced glutathione and was presented as nmoles per $\mathrm{mg}$ of protein.

Preparation of postmitochondrial fraction. Cell cultures were rinsed twice with cold PBS and lysed for 30 min with ice-cold buffer containing: $10 \mathrm{mM}$ Tris/ $\mathrm{HCl}, \mathrm{pH}$ 7.4, $1 \mathrm{mM}$ EGTA, $1 \mathrm{mM}$ EDTA and protease inhibitor cocktail: $1 \mathrm{mM}$ PMSF, $1 \mu \mathrm{M}$ pepstatin, and $10 \mu \mathrm{M}$ leupeptin. The postmitochondrial fraction was obtained after centrifugation at $10000 \times g$ for $15 \mathrm{~min}$ at $4{ }^{\circ} \mathrm{C}$. Protein concentration was measured using Protein Assay kit.

Immunoblots. For Western blotting, 20-60 $\mu \mathrm{g}$ of proteins were separated on $15 \%$ SDS/PAGE followed by transfer to nitrocellulose. Membranes were blocked in TBS containing 3\% BSA and $0.1 \%$ Tween 20 for $1-2 \mathrm{~h}$ and next incubated with primary antibodies: anti-MGST1 (1:1000), anti-MAP kinases: JNK, p-JNK, p38, p-p38, pERK1/2 (1:500) and ERK1/2 (1:750) for $12 \mathrm{~h}$ at $4{ }^{\circ} \mathrm{C}$. For staining, appropriate secondary antibodies $(1: 1000)$ coupled with alkaline phosphatase were used. Blots were developed with Sigma Fast BCIP/NBT according to the manufacturer's instructions. The intensity of bands was quantified by densitometric analysis using GelDoc TMEQ system with Quantity One software (Bio-Rad Laboratories, USA). Immunoblots were normalized to actin content with anti-actin antibody $(1: 3000)$.

Glutathione transferases activity. The determination of GSTs activity in postmitochondrial fraction was done after a $5 \mathrm{~min}$ incubation at $37^{\circ} \mathrm{C}$ with $1 \mathrm{mM} \mathrm{CDNB}$ and $1 \mathrm{mM}$ GSH or $1 \mathrm{mM} \mathrm{DCNB}$ and $5 \mathrm{mM}$ GSH as substrates, according to the procedure of Habig and Jakoby (1981). The activity was presented as nmoles per mg protein per minute.

Microarray analysis. Total RNA was isolated from $1 \times 10^{6}$ cell of both lines using ArrayGrade ${ }^{\mathrm{TM}}$ Total RNA Isolation Kit according to the procedure provided by the manufacturer. The concentration and purity of extracted RNA was determined spectrophotometrically at 260/280 nm. Synthesis, labeling and hybridization of cDNA samples to the GEArray Rat Neurogenesis and Neural Stem Cell Microarray (ORN-40404) were performed according to the manufacturer's instruction. Hybridization and chemiluminescent detection were performed using Chemiluminescent Detection Kit according to the manufacturer's protocol. The imaging screens were scanned and analyzed with GEArray Expression Analysis Suite 2.0 (SuperArray Bioscience Corp.)

Statistics. Statistical analyses were done using the STATISTICA 8.0 Inc. (USA) computer program and $P<0.05$ was considered to indicate statistically significant differences. Data presented are the mean of duplicate or triplicate determinations from at least four independent cell cultures.

\section{RESULTS}

To characterize the role of MGST1 in the functioning and development of PC12 cells we compared the control PC12 cell line (transfected with an empty plasmid) and PC12_M cells (with a reduced MGST1 level). Real-time PCR (Table 1) and Western blot analyses (Fig. 1) indicated that the expression of mRNA MGST1 and protein level decreased to $60 \%$ after transfection of PC12 cells with a plasmid containing the antisense target sequence. The first morphological changes in PC12_M cells were detected after $48 \mathrm{~h}$ (Fig. 2). These cells exhibited a stronger tendency to grow in clusters, weaker adhesion, a multipolar body of cells and displayed the formation of short neurite-like extension in comparison with the control PC12 line.

Viability of the cells estimated by Trypan Blue staining showed a higher percentage of dead cells in PC12_M $(22 \%)$ than in the control line $(6 \%)$. Decreased survival of PC12 cells with reduced MGST1

Table 1. Real-time PCR analysis of mRNA MGST1 level The results are from three independent experiments. $\Delta \mathrm{Ct}$, (average $\mathrm{Ct}_{\text {MGST1, PC12_M }}$ - average $\mathrm{Ct}_{\text {GAPDH' }} \mathrm{PC12}_{\mathrm{M}}$ ) for PC12_M or (average $\mathrm{Ct}$ MGST1, PC12 - average $\mathrm{Ct}_{\text {GAPDH }}$ PC12) for PC12; $\Delta \Delta \mathrm{Ct}$ (average $\Delta \mathrm{Ct}_{\text {MGST1, }}$

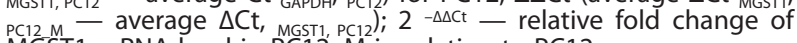
MGST1 mRNA level in PC12_M in relation to PC12.

\begin{tabular}{lll}
\hline & $\mathrm{PC} 12$ & $\mathrm{PC1} 2 \_\mathrm{M}$ \\
\hline$\Delta \mathrm{Ct}$ & $2.27 \pm 0.17$ & $3.10 \pm 0.51$ \\
$\Delta \Delta \mathrm{Ct}$ & 0.00 & $0.83 \pm 0.43$ \\
$2-\Delta \Delta \mathrm{Ct}$ & 1.00 & $\mathbf{0 . 5 9 \pm 0 . 1 6}$ \\
& & $P=0.000205$ \\
\hline
\end{tabular}




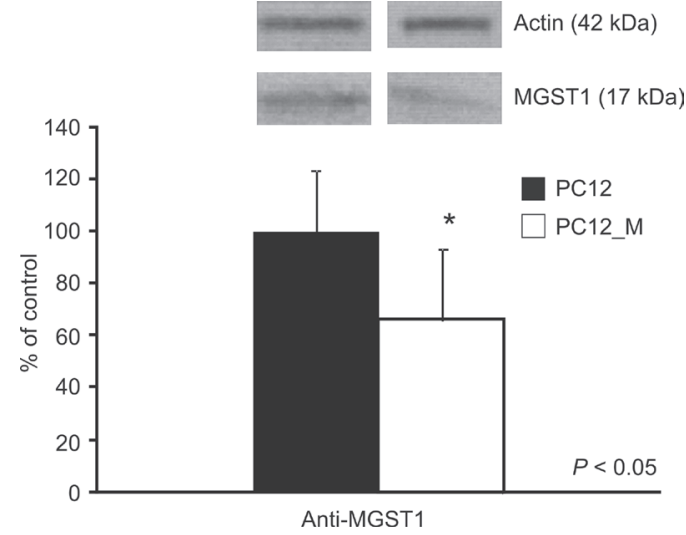

Figure 1. Western blot and densitometric analysis of MGST1 in postmitochondrial fractions of PC12 cell lines

Proteins were analyzed by SDS-polyacrylamide gel electrophoresis on $15 \%$ gels under reducing conditions followed by immunoblotting with anti-MGST1 or anti-actin. Quantification of MGST1 band was performed after densitometric scanning of immunoblots and normalized to actin level. The normalized amount of MGST1 in control PC12 cells was taken as $100 \%$. Data shown are the mean from four independent experiments. ${ }^{*} P<0.05$.

was confirmed by flow cytometry analysis that revealed a higher percentage of necrotic cells (Fig. 3; Table 2).

Immunocytochemical staining revealed differences in the concentration of MGST1 between the two cell lines (Fig. 4). The highest intensity of the fluorescent signal in the control line than in PC12_M cells
Table 2. Quantification of viable, apoptotic and necrotic cells in PC12 lines

Cell status was analyzed by FACS (distribution between different subpopulations of the cells in both cell lines is presented in percentage).

\begin{tabular}{llllc}
\hline Cells & Viable & Early apoptosis & Late apoptosis & Necrosis \\
\hline PC12 & 95.72 & 0.53 & 1.67 & 2.08 \\
PC12_M & 65.72 & 0.00 & 0.14 & 34.14 \\
\hline
\end{tabular}

Table 3. Effect of MGST1 suppression on PC12 cells migration Assays were performed using membrane filters coated with albumin (control substrate) or laminin (chemoattractant). Migration is expressed as the total number of cells that migrated across membrane during a $4 \mathrm{~h}$ incubation period.

\begin{tabular}{lll}
\hline Cells & $\begin{array}{l}\text { Cells migration on } \\
\text { albumin }\end{array}$ & $\begin{array}{l}\text { Cells migration on } \\
\text { laminin }\end{array}$ \\
\hline PC12 & $51 \pm 26$ & $178 \pm 41$ \\
PC12_M & $57 \pm 40$ & $17 \pm 2$ \\
\hline
\end{tabular}

confirmed the reduction of total MGST1 content in PC12_M. However, to determine specific distribution of MGST1 in the cells, further studies using appropriate intracellular markers are needed.

The possible role of MGST1 in tumor progression was analyzed by determining the ability of the cells to migrate. The cells were tested using two substrates albumin as a control and laminin as a chemoattractant.
$\mathrm{Oh}$

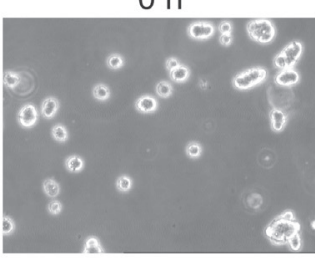

PC12

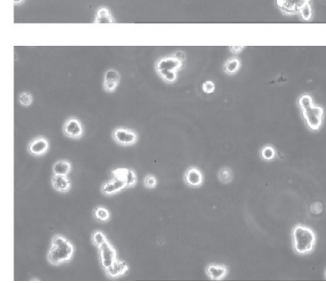

$24 \mathrm{~h}$
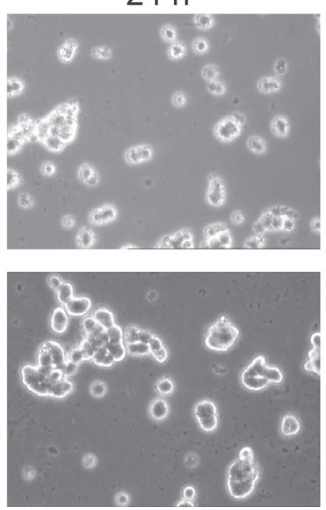

$48 \mathrm{~h}$
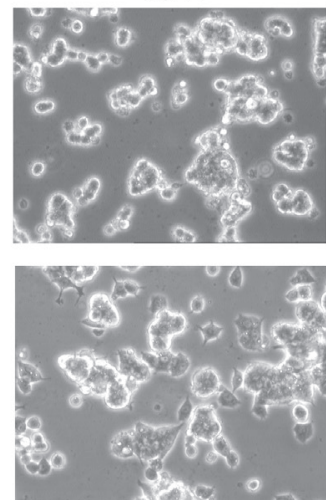

$72 \mathrm{~h}$
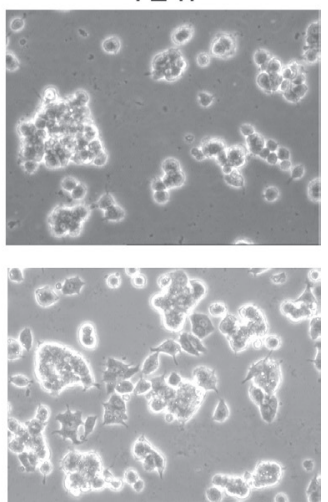

Figure 2. Morphological characteristic of PC12 cell lines

Cells were photographed after 24,48 and $72 \mathrm{~h}$ of cultivation using an inverted Olympus CK-40 microscope at $20 \times$ magnification. PC12, control line transfected with empty plasmid; PC12_M, cell line transfected with plasmid containing anti-MGST1 sequence.

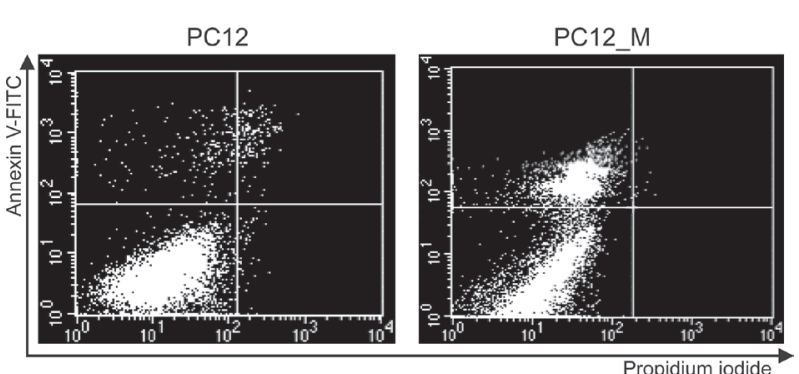

Figure 3. Flow cytometry analysis

FACS analysis was performed for $10^{4}$ cells in each sample using double staining with Annexin V and propidium iodide, after $48 \mathrm{~h}$ of culturing. The lower left quadrant shows viable cells, lower right - early apoptotic cells, upper right quadrant - late apoptotic cells, upper left - necrotic cells.
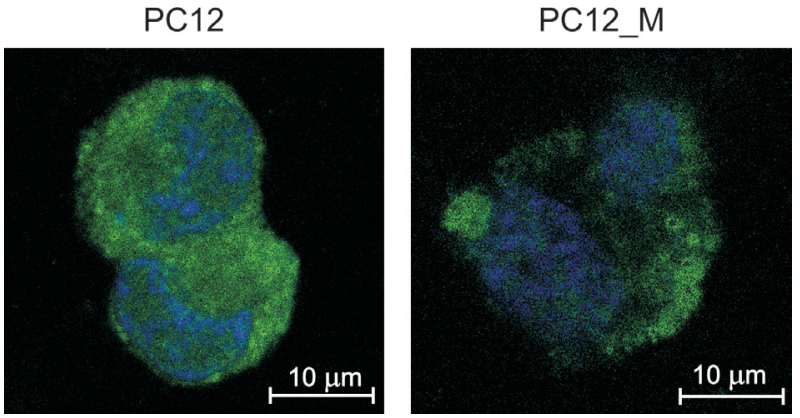

Figure 4. Immunocytochemistry of MGST1 in PC12 cell lines Examination was performed with a confocal laser-scanning microscope TCS SP5 (Leica). Images represent overlapping of many optical sections. The blue signal is from cell nuclei stained with DAPI and the green signal from MGST1 stained with FITC-conjugated secondary antibodies. 
Table 4. Glutathione concentration in PC12 cell lines

Concentration of reduced (GSH) and oxidized (GSSG) glutathione in PC12 cell lines was determined as described in Materials and Methods. Results are averages of four separate experiments performed in duplicate, using different cell cultures. ${ }^{*} P<0.05$ vs. control PC12 line.

\begin{tabular}{llll}
\hline Cells & $\begin{array}{l}\text { GSX } \\
\text { (nmoles/mg protein) }\end{array}$ & $\begin{array}{l}\text { GSSG } \\
\text { (nmoles/mg protein) }\end{array}$ & $\begin{array}{l}\text { GSSG/ } \\
\text { GSH } \\
(\%)\end{array}$ \\
\hline PC12 & $6.7 \pm 1.5$ & $0.3 \pm 0.1$ & 4.7 \\
PC12_M & $\mathbf{8 . 8} \pm \mathbf{1 . 7 ^ { * }}$ & $0.2 \pm 0.1$ & 2.3 \\
\hline
\end{tabular}

GSX, total glutathione; GSSG, disulfide glutathione; GSH, reduced glutathione

Both lines exhibited a similar potential for migration on the control substrate, whereas with laminin the control PC12 cells migrated three times more efficiently than the cells with reduced MGST1 (Table 3).

To examine the MGST1 influence on the antioxidant system we determined glutathione concentration. In PC12_M cells a statistically significantly higher total glutathione content was detected; however, the GSSG/ GSH ratio was almost two-fold lower than in the control (Table 4).

To analyze the consequences of MGST1 suppression on the activity of cytosolic GSTs, which are an integral part of a dynamic and interactive cellular defense mechanism, in the next step the activity of glutathione transferases was assayed in the postmitochondrial fraction using CDNB, a non-specific substrate for all GSTs, and DCNB, which is specific only for cytosolic glutathione transferases. In the presence of CDNB the total activity of GSTs in PC12_M cells was lower by $15-20 \%$ from that in the control, whereas with DCNB the activity was similar in both examined lines (Fig. 5).

Based on the observed morphological and biochemical changes in the PC12_M line, we decided to characterize the activity of MAP kinases: p38, JNK and ERK1/2. Mitogen-activated protein kinases, an enzyme family involved in various cellular responses to external or endogenous signals, play a predominant role in stress response and in many normal physiological processes. Among others, the MAPK signalling pathway regulates cellular proliferation and differentiation, cell migration, apoptosis, and malignant transformation. In the cells with suppressed MGST1 the total protein content of p38, ERK1 and ERK2 was lower than in the control cells, but their phosphorylation level was higher. In contrast, for JNK

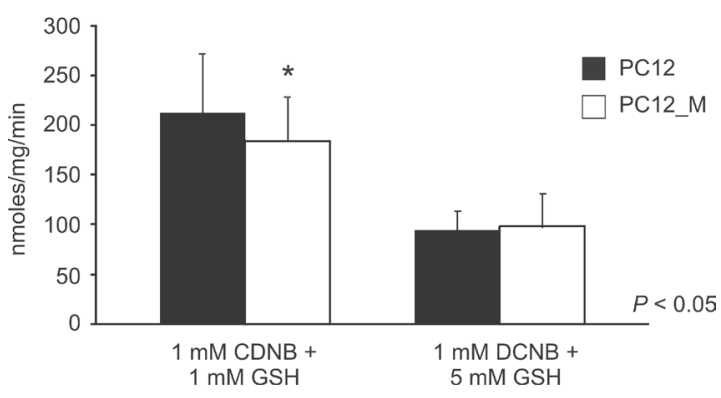

Figure 5. GSTs activity in postmitochondrial fraction Samples were incubated with substrates at $37^{\circ} \mathrm{C}$ for $5 \mathrm{~min}$ and the activity was determined spectrophotometrically. The results are averages of four independent experiments performed in duplicate, using different cell cultures. ${ }^{*} P<0.05$.

the increase in a total protein content was accompanied by a lower intensity of phosphorylation (Fig. 6).

To elucidate if the suppression of MGST1 could have any influence on the profile of gene expression, we performed a large-scale analysis using a commercially available microarray with selected 263 genes involved in neurogenesis, synaptic functions, cell cycle control, apoptosis, migration and motility, proliferation, differentiation and adhesion. Microarray experiments were repeated four times with representative images shown in Fig. 7. In PC12_M cells the expression of eight genes was higher and of eleven genes lower than in the control (Fig. 8). In both examined lines the microarray analysis also revealed several genes with similar high expression levels (ache, bmp2, 11 cam, ninj, nrg1, pafab1b1, rac1 and tiam1). This suggests that the altered PC12_M metabolism did not affect their cellular function.

\section{DISCUSSION}

MGST1 has glutathione transferase and peroxidase activities and due to these specific properties plays a major role in detoxication of drugs and xenobiotics. It is also involved in anticancer drug resistance, may protect membranes against lipid peroxidation, mainly its toxic products such as 4-HNE, and participates in signaling pathways mediated by ROS - its substrates (Johansson et al., 2007; Siritantikorn et al., 2007, Lee et al., 2008). This unique characteristic of MGST1 demonstrates its essential role in cell metabolism.
A

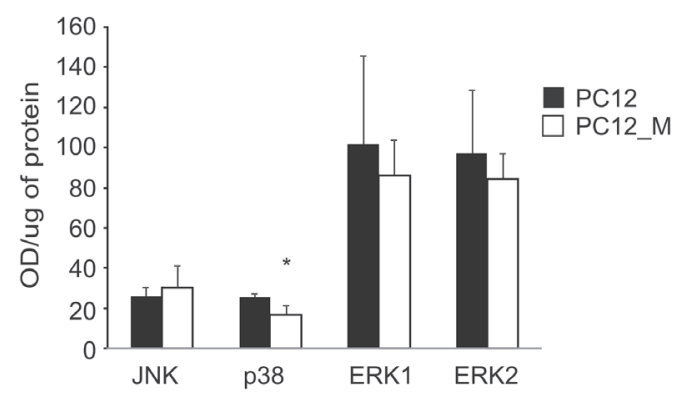

B

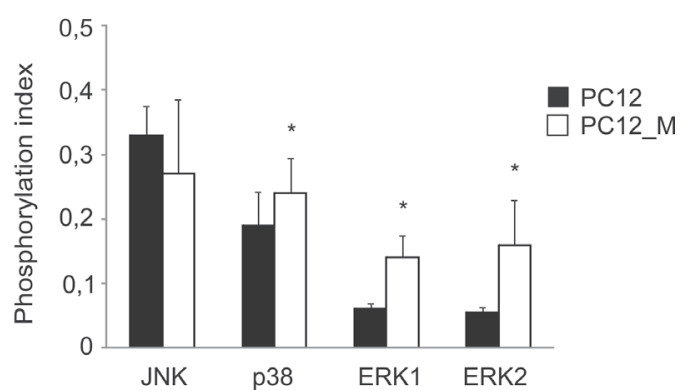

Figure 6. Analysis of MAP kinases in PC12 cell lines

The intensity of protein kinase bands was quantified by densitometric analysis of immunoblots. The results are averages of four independent experiments performed in duplicate, using different cell cultures. ${ }^{*} P<0.05$. (A) The amount of examined kinases was normalized to $\beta$-actin and is expressed in arbitrary units. (B) Phosphorylation index for each kinase is expressed as the ratio of normalized amount of phosphorylated kinase to the total amount of kinase protein. 


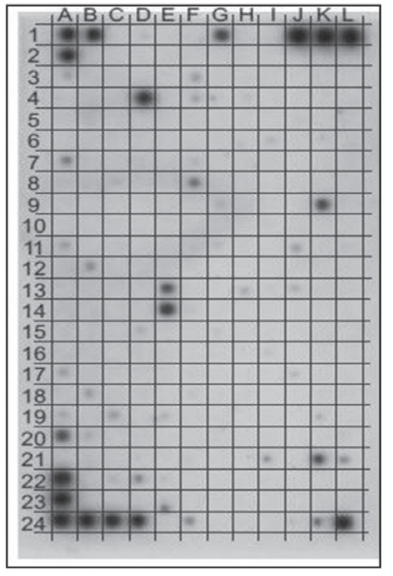

PC12

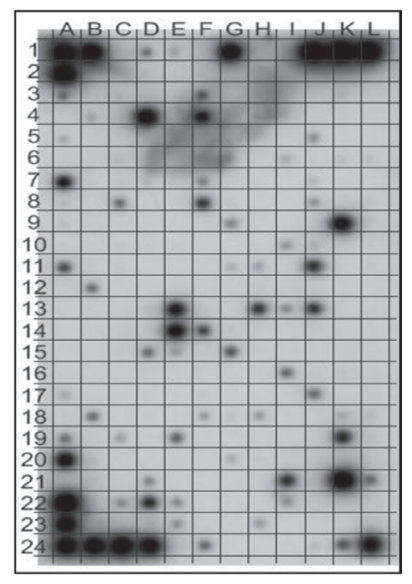

PC12 M
Figure 7. Microarray analysis of PC12 cell lines

Gene expression was analyzed using Rat Neurogenesis and Neural Stem Cell Microarray (ORN-404-04). Representative arrays are shown.

Enzymatic and non-enzymatic defense (such as glutathione) provide the first line of antioxidant protection against free radicals generated in the mitochondrial electron transport chain. Overproduction of ROS or diminished GSTs activity can initiate an autocatalytic increase in the membrane lipid peroxidation, resulting in the formation of a variety of toxic electrophilic species. These disturbances may be reflected at several levels, e.g., the cellular metabolism and the pattern of gene expression. To characterize the cellular effect of MGST1 suppression first we determined the total glutathione amount. A surprising observation was that the total glutathione content was higher in the PC12_M line than in the control, whereas the GSSG/GSH ratio a good indicator of the cellular redox state was lower. This may suggests a reduced consumption of glutathione or its higher de novo biosynthesis. Glutathione participates in many cellular processes, such as antioxidant protection and nutrient metabolism, and is a regulator of cell division, apoptosis, signal transduction and protein glutathionylation (Wu et al., 2004). Our results indicate that the antioxidant reserve of PC12_M cells is increased relative to the normal level and it could be a compensatory mechanism, which enables the survival of about $70 \%$ of the cells.

Mitochondria represent the major ROS source for the cell and posses unique antioxidant defense systems, including a specific pool of glutathione transferases (Jezek \& Hlavata, 2005). It has also been shown that mitochondrial respiratory and redox functions are specifically affected under stress conditions (Raza \& John, 2006). In the present study we analyzed the GSTs activity in the postmitochondrial fraction to discriminate the effect of MGST1 suppression on the GSTs activity between mitochondria and other cellular compartments. In PC12_M cells a decreased total GSTs activity towards CDNB was noticed, whereas with DCNB as a substrate, the activity was similar to that in the control line. This suggests that the decline in MGST1 cannot be compensated by an increase of the activity of other cytosolic GSTs and it underlines the exceptional function of this enzyme. Further detailed study is needed to elucidate the mitochondrial participation in the observed effects.

Although the reduction of MGST1 increased the overall level of necrotic cells, it simultaneously triggered differentiation of the remaining PC12_M cells. Rat pheochromocytoma PC12 cells upon exposure to neurotrophin or dibutyryl-cAMP can be induced to differentiate into sympathetic neurons (Lambeng et al., 2001). In PC12_M line we observed an altered cell morphology - from that typical for cancer cells to pseudoneuronal one. However, the observed neurite outgrowth without any external differentiation factors was distinctly different from that after neurotrophin stimulation reported by several studies. Preliminary analyses using a commercially available microarray showed that MGST1 suppression changed the profile

A

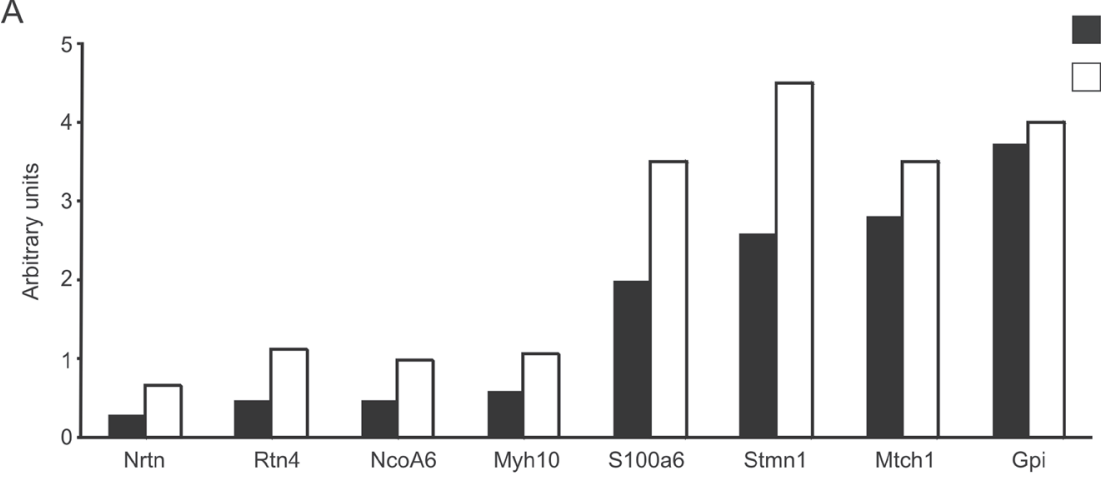

$\mathrm{PC} 12$

PC12M

B

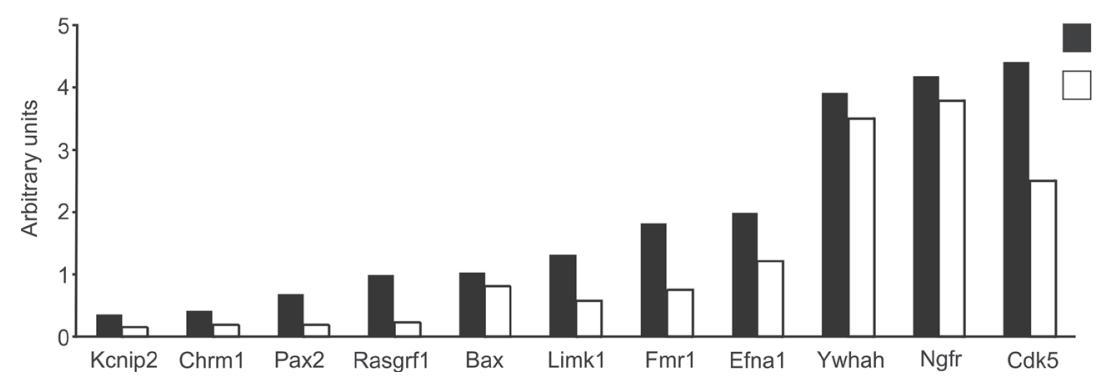

Figure 8. Comparison of gene expression in PC12 cell lines The analyses were performed using Rat Neurogenesis and Neural Stem Cell Microarray as described under Materials and Methods. Gene expression was normalized to glyceraldehyde-3-phosphate dehydrogenase, peptidylprolyl isomerase $A$, lactate dehydrogenase $A$, ribosomal protein $L 32,5 S$ rRNA gene, aldolase A and ribosomal protein S27a. After intraand inter-array standardization and normalization, genes demonPC12 strating undetectable expression
PC12 M levels in at least half of the control or experimental groups were eliminated. Significant differences between control PC12 and PC12 M were observed for 19 genes $(P<0.05)$. Bars indicate the expression level of a given gene in examined cell lines. (A) Genes up-regulated in PC12 M cells. (B) Genes down regulated in PC12_M cells. 
of genes expression. These alterations could be relevant to the survival, change in a phenotype and modification of signaling pathways in PC12_M cells, particularly crucial for neurogenesis and synaptic processes. At present it is difficult to explain conclusively this phenomenon, but we detected elevated expression of nrtn gene, encoding a neurotrophin with a strong effect on neurite outgrowth (Oiwa et al., 2002).

Another potentially interesting observation was the increased expression of stmn1, which is present in a high amount in the central nervous system and plays a significant role during NGF-stimulated differentiation of PC12 cells, and is also involved in cell proliferation (DiPaolo et al., 1996; Mistry \& Atweh, 2002). The outgrowth of small neurites in PC12_M cells could be due to increased expression of $r$ tn 4 gene - a potent inhibitor of axonal growth. The Rtn 4 protein, by interacting with adhesion molecules like integrins, decreases the cells ability to adhere to the substrate (Yang \& Strittmatter, 2007; Hu \& Strittmatter, 2008). Also another protein, Efna1, which regulates dendrite morphology and formation of new neuronal connections (Wykosky \& Debinski, 2008) was expressed in PC12_M cells at a diminished level.

Necrosis is often defined as uncontrolled process of cell death, but recent studies have shown that cells can change the type of death from apoptosis or autophagy to necrosis. It could be linked with inhibition or lowered expression of regulatory proteins required for apoptosis such as Bax (Golstein \& Kroemer, 2006). Apoptosis of neuronal cells depends on the cellular balance between pro-apoptotic (Bax, Box, Bad) and antiapoptotic proteins (Bcl-2, Bcl-x, Bcl-w) (Tehranian et al., 2008). The observed higher amount of necrotic cells in the PC12_M line might result from disturbances in the control of Bax-regulated apoptosis. Moreover, this process could also be enhanced by the apparent decrease in phosphorylation level of c-Jun N-terminal kinase (JNK). The enzyme is responsible for regulation of transcription of several genes related to apoptosis, including bax and 14-3-3 protein family (Wagner \& Nebreda, 2009). It is notable that one of these proteins is Ywhah, whose diminished expression at the transcript level was detected in PC12_M. We also found an altered expression of two other genes coding for proteins that regulate apoptotic events - Ngfr, a pro-apoptotic receptor, and Rtn4, which binds to proteins from the $\mathrm{Bcl} 2$ family and inhibits their anti-apoptotic activity (Yang \& Strittmatter, 2007; Bertrand et al., 2008). An interesting observation was the increased expression of $\mathrm{S} 100 \mathrm{a} 6$ (calcyclin) in the PC12_M line. The gene for this calcium binding protein has an ARE sequence (antioxidant responsive element) in the promoter region and the protein plays an important role in protecting cells from oxidative stress (Filipek et al., 2007). Some data have demonstrated differential effects of S100A6 on apoptosis, which depend on the specific cell type and preferential activation of either pro- or anti-apoptotic signaling pathways. Thus, the final result of these regulations appears to be governed by the integration of survival and death signals.

Cell migration is crucial in multiple physiological processes including nervous system development — axon extension, synapse formation, nerve regeneration after injury as well as wound healing, angiogenesis, inflammation, tumor invasion and metastasis (Tomaselli et al., 1987; Rankin et al., 2006). A strong positive correlation between level of glutathione- $S$-transferase $\mathrm{Pi}$ expression and increased metastasis was shown in primary gastric cardiac adenocarcinoma (Shi et al., 2008). In our model, the suppression of MGST1 significantly reduced the ability of cells to migrate. One of the causes could be a diminished expression of Limk1, a kinase that plays a critical role in phosphorylation of the cofilin family proteins (Scott \& Olson, 2007). Limk1 overexpression in human prostate and breast cancer cell lines correlated with higher levels of both phosphorylated cofilin and metastasis (Davila et al., 2003; Bagheri-Yarmand et al., 2006). L1 cam also regulates intercellular interactions and participates in adhesion and migration processes (Raveh et al., 2009). An additional regulatory factor could be modification of the MAP kinases pathway, especially JNK and ERK1/2, which has been shown to induce the expression of some proteins involved in metastasis (Kim \& Choi, 2010). The altered migration, morphology and enhanced necrosis in PC12_M could be a result of a concerted action of all genes that act as regulators of cytoskeletal elements, synaptogenesis and cell survival.

Of the genes engaged in regulation of migration, we observed the disparity between nrg1, pafab1b1, myb10 and $c d k 5$ expression in PC12_M line. However, whereas the level of myb10 was increased, cdk5 was down-regulated and $n r g 1$ and pafah1b1 were expressed at a similar level as in control cells. Cdk5, a very effective serine/threonine kinase, has been shown to phosphorylate a spectrum of proteins, mostly those associated with cell morphology and motility (Tripathi et al., 2010). Moreover, deregulation of Cdk5 has been implicated in several neurodegenerative diseases (for a review see Dhariwala \& Rajadhyaksha, 2008). The changed expression of other genes necessary for neurogenesis and synaptic transmission - mtch1, gpi, rasgrf1, kcnip2, chrm1, fmr1, ywhah, tiam1, ache - as well as of a group of genes that regulate cell proliferation and cell cycle - pafah1b1, rasgrf1, ywhah and bax - clearly indicates that suppression of MGST1 triggered complex gene expression changes. Elucidation of the exact molecular mechanisms of these changes needs further detailed study.

Taken together, our results suggest that activity of MGST1 could be an important regulator of PC12 cells development. Understanding the mechanisms by which MGST1 can influence the expression of genes with different biological functions is of primary importance for the design of new therapeutic approaches to cancerogenesis and neurodegenerative diseases.

\section{Acknowledgements}

The authors thank Dr. Christos Kargas for preliminary experiments, Prof. Slawomir Pikula and Michalina Kosiorek (Nencki Institute of Experimental Biology, Department of Biochemistry, Warszawa, Poland) for advice and assistance with the confocal microscope. We are also grateful to Eleonora Welhan for her excellent technical assistance.

Supported by grants 2 P05A 03529 and PBZMIN-012/P04/2004 from the Ministry of Science and Higher Education (Poland) and 503-6806-2, 502-16-810 and 502-16-809 from the Medical University of Lodz.

\section{REFERENCES}

Bagheri-Yarmand R, Mazumdar A, Sahin AA, Kumar R (2006) LIM kinase 1 increases tumor metastasis of human breast cancer cells via regulation of the urokinase-type plasminogen activator system. Int J Cancer 118: 2703-2710.

Bertrand MJM, Kenchappa RS, Andrieu D, Leclerq-Smekens M, Nguyen HNT, Carter BD, Muscatelli F, Barker PA, De Backer O (2008) 
NRAGE, a p75NTR adaptor protein, is required for developmental apoptosis in vivo. Cell Death Differ 15: 1921-1929.

Dhariwala FA and Rajadhyaksha MS (2008) An unusual member of the Cdk family: Cdk5. Cell Mol Neurobiol 28: 351-369.

Davila M, Frost AR, Grizzle WE, Chakrabarti R (2003) LIM Kinase 1 is essential for the invasive growth of prostate epithelial cells. J Biol Chem 278: 36868-36875.

Di Paolo G, Pellier V, Catsicas M, Antonsson B, Catsicas S, Grenningloh G (1996) The phosphoprotein stathmin is essential for nerve growth factor-stimulated differentiation. J Cell Biol 133: 1383-1390.

Estonius M, Forsberg L, Danielsson O, Weinander R, Kelner MJ, Morgenstern R (1999) Distribution of microsomal glutathione transferase 1 in mammalian tissue. A predominant alternate first exon in human tissues. Eur J Biochem 260: 409-413.

Filipek A, Michowski W, Kuznicki J (2007) Involvement of S100A6 (calcyclin) and its binding partners in intracellular signaling pathways. Advan Enzyme Regul 48: 225-239.

Golstein P, Kroemer G (2006) Cell Heath by necrosis: towards a molecular definition. Trends Biochem Sci 32: 37-43.

Habig WH, Jakoby WB (1981) Assays for differentiation of glutathione-S-transferases. Methods Enzymol 77: 398-405.

Hu F, Strittmatter SM (2008) The N-terminal domain of nogo-a inhibits cell adhesion and axonal outgrowth by an integrin-specific mechanism. J Neurosici 28: 1262-1269.

Imaizumi N, Miyagi S, Aniya Y (2006) Reactive nitrogen species derived activation of rat liver microsomal glutatione S-transferase. Life Sci 78: 2998-3006.

Jakobbson Per-Johan, Morgenstern R, Mancini J, Ford-Hutchinson A, Persson B (2000) Membrane-associated proteins in eicosanoid and glutathione metabolism (MAPEG). A widespread protein superfamily. Am J Respir Crit Care Med 161: 20-24.

Jezek P, Hlavatá L (2005) Mitochondria in homeostasis of reactive oxygen species in cell, tissues, and organism. Int J Biochem Cell Biol 37: $2478-503$.

Johansson K, Ảhlen K, Rinaldi R, Sahlander K, Siritantikorn A and Morgenstern R (2007) Microsomal glutathione transferase 1 in anticancer drug resistance. Carcinogenesis 28: 465-470.

Kim EK, Choi E-J (2010) Pathological roles of MAPK signaling pathways in human diseases. Biochim Biophys Acta 1802: 396-405.

Lambeng N. Michel PP, Agid Y, Ruberg M (2001) The relationship between differentiation and survival in PC12 cells treated with cyclic adenosine monophosphate in the presence of epidermal growth factor or nerve growth factor. Neurosci Lett 297: 133-136.

Lee SH, DeJong J (1999) Microsomal GST-I: genomic organization, expression, and alternative splicing of the human gene. Biochim Biophys Acta 1446: 389-396.

Lee KK, Shimoji M, Hossain QS, Sunakawa H, Aniya Y (2008) Novel function of glutathione transferase in rat liver mitochondrial membrane: Role for cytochrome c release from mitochondria. Toxicol Appl Pharmacol 232: 109-118.

Livak KJ, Schmittgen TD (2001) Analysis of relative gene expression data using real-time quantitative PCR and the $2^{-\Delta \Delta \mathrm{Ct}}$ method. Methods 25: 402-408.

Mistry SJ, Atweh GF (2002) Role of stathmin in the regulation of the mitotic spindle: potential applications in cancer therapy. Mt Sinai J Med 69: 299-305.

Oiwa Y, Yoshimura R, Nakai k, Itakura T (2002) D opaminergic neuroprotection and regeneration by neurturin assessed by using behav- ioral, biochemical and histochemical measurements in a model of progressive Parkinson's disease. Brain Res 947: 271-283.

Rankin SL, Rahimtula M, Mearow KM (2006) A method to assess multiple aspects of the motile behaviour of adherent PC12 cells on applied biological substrates. J Neurosci Methods 156: 55-63.

Raveh S, Gavert N, Ben-Ze'ev A (2009) L1 cell adhesion molecule (L1 cam) in invasive tumors. Cancer Lett 282: 137-145.

Raza H, John A (2006) 4-hydroxynonenal induces mitochondrial oxidative stress, apoptosis and expression of glutathione S-transferase A4-4 and cytochrome P450 2E1 in PC12 cells. Toxicol Appl Pharmacol 216: 309-18.

Scott RW, Olson MF (2007) LIM kinases: function, regulation and association with human disease. J Mol Med 85: 555-568.

Shi H, Lu D, Shu Y, Shi W, Lu S, Wang K (2008) Expression of multidrug resistance-related proteins $p$-glycoprotein, glutathione- $S$ transferases, topoisomerase-II and lung resistance protein in primary gastric cardiac adenocarcinoma. Cancer Invest 26: 344-351.

Siritantikorn A, Johansson K, Åhlen K, Rinaldi R, Suthiphongchai T, Wilairat P, Morgenstern R (2007) Protection of cells from oxidative stress by Microsomal glutathione transferase 1. Biochem Biophys Res Commun 355: 592-596.

Tehranian R, Rose ME, Vagni V, Pickrell AM, Griffith RP, Liu H, Clark RSB, Edward Dixon C, Kochanek PM, Graham SH (2008) Disruption of bax protein prevents neuronal cell death but produces cognitive impairment in mice following traumatic brain injury. $J$ Neurotrauma 25: 755-767.

Tomaselli KJ, Damsky CH, Reichardt LF (1987) Interactions of a neuronal cell line (PC12) with laminin, collagen IV, and fibronectin: identification of integrin-related glycoproteins involved in attachment and process outgrowth. J Cell Biol 105: 2347-2358.

Tripathi BK, Zelenka PS (2010) Cdk5. A regulator of epithelial cell adhesion and migriation. Cell Adhesion \& Migration 4: 1-4.

Uttara B, Singh AV, Zamboni P, Mahajan RT (2009) Oxidative stress and neurodegenerative diseases: a review of upstream and downstream antioxidant therapeutic options. Cur Neuropharmacol 7: 65-74.

Von Bernhardi R, Tichauer JE, Eugenin J (2010) Aging-dependent changes of microglial cells and their relevance for neurodegenerative disorders. J Neurochem 112: 1099-1114.

Wagner EF, Nebreda AR (2009) Signal integration by JNK and p38 MAPK pathways in cancer development. Nat Rev Cancer 9: 537-549.

Wu G, Fang Y-Z, Yang S, Lupton JR, Turner ND (2004) Glutathione metabolism and its implications for health. I Nutr 134: 489-492.

Wykosky J, Debinski W (2008) The EphA2 receptor and ephrinA1 ligand in solid tumors: function and therapeutic targeting. Mol Cancer Res 6: 1795-806.

Yanbin J, Neverova I, Van Eyk JE, Bennett BM (2006) Nitration of tyrosine 92 mediates the activation of rat microsomal glutathione S-transferase by peroxynitrite. J Biol Chem 281: 1986-1991.

Yang Y, Sharma R, Sharma A, Awasthi S, Awasthi YC (2003) Lipid peroxidation and cell cycle signaling: 4-hydroxynonenal, a key molecule in stress mediated signaling. Acta Biochim Pol 50: 319-336.

Yang YS, Strittmatter SM (2007) The reticulons: a family of proteins with diverse functions. Genome Biol 8: 234.

Zylinska L, Kozaczuk A, Szemraj J, Kargas Ch, Kowalska I (2007) Functional importance of PMCA isoforms in growth and development of PC12 Cells. Ann NY Acad Sci USA 1099: 254-269. 